\title{
Curcumin-loaded nanoparticles induce apoptotic cell death through regulation of the function of MDR1 and reactive oxygen species in cisplatin-resistant CAR human oral cancer cells
}

\author{
PEI-YING CHANG ${ }^{1,6}$, SHU-FEN PENG ${ }^{2}$, CHAO-YING LEE ${ }^{5}$, CHI-CHENG LU ${ }^{4}$, SHIH-CHANG TSAI ${ }^{2}$, \\ TZONG-MING SHIEH ${ }^{3}$, TIAN-SHUNG WU ${ }^{7}$, MING-GENE TU ${ }^{1,6}$, \\ MICHAEL YUANCHIEN CHEN ${ }^{1,6}$ and JAI-SING YANG ${ }^{4}$
}

\begin{abstract}
Departments of ${ }^{1}$ Dentistry, ${ }^{2}$ Biological Science and Technology, ${ }^{3}$ Dental Hygiene and ${ }^{4}$ Pharmacology, ${ }^{5}$ School of Pharmacy, China Medical University; ${ }^{6}$ Dental Department and Division of Oral Maxillofacial Surgery,

China Medical University Hospital, Taichung 404; ${ }^{7}$ Department of Chemistry,

National Cheng Kung University, Tainan 701, Taiwan, R.O.C.
\end{abstract}

Received June 3, 2013; Accepted July 9, 2013

DOI: 10.3892/ijo.2013.2050

\begin{abstract}
Curcumin is a polyphenolic compound which possesses anticancer potential. It has been shown to induce cell death in a variety of cancer cells, however, its effect on CAL27-cisplatin-resistant human oral cancer cells (CAR cells) has not been elucidated to date. The low water solubility of curcumin which leads to poor bioavailability, however, has been highlighted as a major limiting factor. In this study, we utilized water-soluble PLGA curcumin nanoparticles (Cur-NPs), and investigated the effects of Cur-NPs on CAR cells. The results showed Cur-NPs induced apoptosis in CAR cells but exhibited low cytotoxicity to normal human gingival fibroblasts (HGFs) and normal human oral keratinocytes (OKs). Cur-NPs triggered DNA concentration, fragmentation and subsequent apoptosis. Compared to untreated CAR cells, a more detectable amount of Calcein-AM accumulation was found inside the treated CAR cells. Cur-NPs suppressed the protein and mRNA expression levels of MDR1. Both the activity and the expression levels of caspase- 3 and caspase- 9 were elevated in the treated
\end{abstract}

Correspondence to: Dr Jai-Sing Yang, Department of Pharmacology, China Medical University, No. 91, Hsueh-Shih Road, Taichung 40402, Taiwan, R.O.C.

E-mail: jaising@mail.cmu.edu.tw

Dr Michael Yuanchien Chen, Dental Department and Division of Oral Maxillofacial Surgery, China Medical University Hospital, No. 2, Yu Der Road, Taichung 40447, Taiwan, R.O.C.

E-mail: mychen@www.cmuh.org.tw

Key words: curcumin nanoparticles, apoptosis, multiple drug resistance 1 , reactive oxygen species, CAL27-cisplatin resistant human oral cancer cells
CAR cells. The Cur-NP-triggered apoptosis was blocked by specific inhibitors of pan-caspase (z-VAD-fmk), caspase-3 (z-DEVD-fmk), caspase-9 (z-LEHD-fmk) and antioxidant agent (N-acetylcysteine; NAC). Cur-NPs increased reactive oxygen species (ROS) production, upregulated the protein expression levels of cleaved caspase-3/caspase-9, cytochrome $c$, Apaf-1, AIF, Bax and downregulated the protein levels of Bcl-2. Our results suggest that Cur-NPs triggered the intrinsic apoptotic pathway through regulating the function of multiple drug resistance protein 1 (MDR1) and the production of reactive oxygen species (ROS) in CAR cells. Cur-NPs could be potentially efficacious in the treatment of cisplatin-resistant human oral cancer.

\section{Introduction}

Head and neck squamous cell carcinoma (HNSCC) ranks the sixth most common cancer in the world, and the survival rate has not improved significantly in the last 20 years despite the countless studies on this malignancy $(1,2)$. In Taiwan, HNSCC has become the fourth most common cause of cancer death in males $(3,4)$. Most of Taiwanese victims of HNSCC are diagnosed with oral squamous cell carcinoma (OSCC) due to the wide prevalence of betel-quid chewing $(3,5)$. Depending on tumor staging, the treatment options of OSCC include surgery, radiotherapy and chemotherapy $(6,7)$. The significant morbidities caused by cisplatin-based chemotherapy have led to continuing research on less toxic therapeutic agents $(8,9)$. Drug resistance to cisplatin in patients with recurrent or metastatic OSCC is another challenge in oncology clinical practice $(10,11)$.

Curcumin is a hydrophobic polyphenol derived from the plant Curcuma longa (tumeric) and has been used in Traditional Oriental Medicine for thousands of years (12-14). It is reported to possess a variety of pharmacologic effects including antiamyloid, anti-bacterial, anti-depressant, anti-inflammatory, antioxidant and anticancer properties $(12,13,15)$. It has also 
been proven to be a modulator of intracellular signaling pathways and to target multiple molecules that inhibit cancer cell proliferation, induce apoptosis (activation of caspases and downregulation of anti-apoptotic gene products) (16-20) or autophagy $(18,19,21)$, to inhibit invasion (MMP-9 and cell adhesion molecules) (22-24) and to suppress inflammation molecules (such as NF- $\mathrm{B}$, TNF, IL-6, IL-1, COX-2 and 5 -LOX) $(25,26)$. The anticancer potential of curcumin has entered into phase II and phase III clinical trials for colon and pancreatic cancers $(27,28)$.

Various animal models and human studies proved that curcumin is non-toxic even at high doses $(13,29)$. In spite of its efficacy and safety, the low water solubility, which leads to poor bio-availability of curcumin has been considered to be a major limiting factor (30-32). The contributing reasons for reduced bio-availability of curcumin are poor absorption, high rate of metabolism and rapid systemic elimination (30-32). New drug delivery systems by oral administration are one of the means to enhance the bio-availability of curcumin. Poly(lactic-co-glycolic acid) (PLGA), a bio-degradable and bio-compatible copolymer that is approved by US Food and Drug Administration (FDA) as a therapeutic device, has been reported as a carrier of curcumin through oral administration improving bio-availability of curcumin at different levels (33-39), however, the molecular mechanism is still unclear. The factors that can affect oral bio-availability of drugs include permeability, efflux transporters (e.g., P-glycoprotein, P-gp, MDR), and enzyme induction or inhibition on intestinal epithelial cells $(40,41)$. Studies show that the intestinal P-gp efflux pump and enterocyte-based metabolism make for a major barrier to the oral bioavailability for various compounds $(40,42,43)$.

To improve the oral bio-availability of curcumin, we designed and developed Cur-NPs (PLGA nanoparticles loaded with curcumin) (Fig. 1A). The purpose of the research was to investigate the molecular mechanisms triggered by Cur-NPs in CAR (CAL27-cisplatin resistant) cell line which was established in our laboratory and is unique in its resistance to cisplatin treatment, and to clarify the mechanism of CUR-PLGA-NPs to enhance bioavailability.

\section{Materials and methods}

Chemicals and reagents. Cisplatin, 3-(4,5-dimethylthiazol-2-yl)-2,5-diphenyltetrazolium bromide (MTT), poly(D,L-lactide-co-glycolide) (PLGA, copolymer ratio 75:25; molecular weight, 66,000-92,000), polyvinyl alcohol (PVA; average molecular weight, 30,000-70,000) and curcumin were purchased from Sigma-Aldrich Corp. (St. Louis, MO, USA). Fetal bovine serum (FBS), L-glutamine, penicillin G, trypsin-EDTA, 4',6-diamidino-2-phenylindole (DAPI), 2',7'-dichlorodihydrofluorescein diacetate $\left(\mathrm{H}_{2} \mathrm{DCFDA}\right)$ and calcein-AM were obtained from Life Technologies (Carlsbad, CA, USA). Caspase-3 and caspase-9 activity assay kits were purchased from R\&D Systems Inc. (Minneapolis, MN, USA). The primary antibodies against caspase-3, caspase-9, Endo G and Bcl-2 were obtained from Cell Signaling Technology Inc. (Beverly, MA, USA). All other antibodies used in this study and horseradish peroxidase (HRP)-conjugated secondary antibodies against rabbit or mouse immunoglobulin were purchased

A

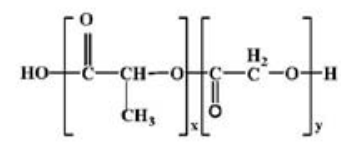

Poly (lactic-co-glycolic acid); PLGA

( $x$ : lactic acid, $\mathbf{y}$ : glycolic acid)

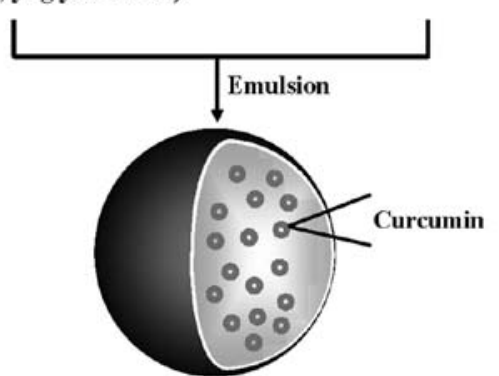

Curcumin-loaded PLGA nanoparticles (Cur-NPs)

B

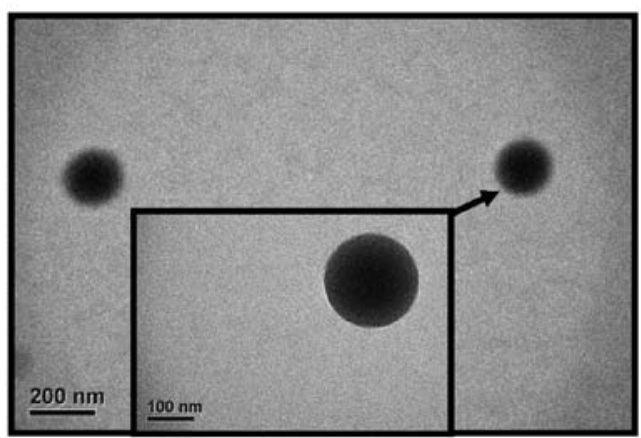

Figure 1. (A). The schematic diagram of Cur-NPs preparation. The curcumin was encapsulated in the PLGA by single emulsion. (B). Morphology observation of Cur-NPs by TEM. The Cur-NPs show spherical in shape.

from Santa Cruz Biotechnology Inc. (Santa Cruz, CA, USA). The specific caspase inhibitors (z-VAD-fmk, z-DEVD-fmk and z-LEHD-fmk) and enhanced chemiluminescence (ECL) detection kit (Immobilon Western Chemiluminescent HRP Substrate) were obtained from Merck Millipore (Billerica, MA, USA).

Cell culture. The human head and neck carcinoma cell line CAL27 was obtained from the American Type Culture Collection (ATCC, Manassas, VA, USA). The cisplatinresistant cell line CAR (CAL27-cisplatin resistant) was established by clonal selection of CAL27 using 10 cycles of 1 passage treatment with $10-100 \mu \mathrm{M}$ of cisplatin followed by a recovery period of another passage (44). CAR cells were cultivated in Dulbecco's modified Eagle's medium (DMEM, Life Technologies) supplemented with $10 \%$ FBS, $100 \mu \mathrm{g} / \mathrm{ml}$ streptomycin, $100 \mathrm{U} / \mathrm{ml}$ penicillin G, $2 \mathrm{mM}$ L-glutamine and $100 \mu \mathrm{M}$ cisplatin for our study. Normal human gingival fibroblasts cells (HGF) and normal human oral keratinocyte cells (OK) cells were kindly provided by Dr Tzong-Ming Shih (45). Normal human gingival fibroblasts cells (HGF) and normal human oral keratinocyte cells (OK) were cultivated in DMEM (Life Technologies) supplemented with $10 \% \mathrm{FBS}, 100 \mu \mathrm{g} / \mathrm{ml}$ streptomycin, $100 \mathrm{U} / \mathrm{ml}$ penicillin $\mathrm{G}, 2 \mathrm{mM}$ L-glutamine and $80 \mu \mathrm{M}$ cisplatin. 
Curcumin loaded nanoparticles. Curcumin-loaded PLGA nanoparticles (Cur-NPs) were prepared by using single emulsion solvent evaporation method. In brief, cucurmin (1 mg) and PLGA (10 mg) were dissolved in dichloromethane. The curcumin and PLGA solution $(1 \mathrm{ml})$ was added to $2 \mathrm{ml}$ of $10 \%(w / v)$ PVA surfactant solution to form an oil-in-water emulsion by sonication. The emulsion was carried out by setting sonication at $55 \mathrm{~W}$ of energy output for 3 min over an ice bath. The formed emulsion was dispersed drop-wise into the $0.5 \%(\mathrm{w} / \mathrm{v})$ PVA solution and stirred for additional $4 \mathrm{~h}$ at room temperature on a magnetic stir plate to allow evaporation of organic solvent. Nanoparticles were collected by centrifugation at $12,000 \mathrm{rpm}$ for $30 \mathrm{~min}$ and washed twice with double distilled water to remove PVA and un-encapsulated curcumin. The prepared nanoparticles were collected and lyophilized $(46,47)$.

Transmission electron microscopy (TEM) observation. The morphology of test nanoparticles was examined by TEM (JEOL, Tokyo, Japan). A dilute suspension of nanoparticles (1/10 dilution) was prepared in double distilled water. One drop of this solution was placed on the TEM grid for $10 \mathrm{~min}$, washed twice with double distilled water and allowed to dry overnight. The images were observed and captured at an accelerating voltage of $120 \mathrm{kV}$ under a microscope $(35,48,49)$.

Cell viability and apoptotic morphological features. The cell viability was assessed by the MTT assay. Briefly, CAR cells, normal human gingival fibroblasts cells (HGF) and normal human oral keratinocyte cells $(\mathrm{OK})$ were cultured in a 96-well plate at the density of $1 \times 10^{4}$ cells per well and were incubated with $0,10,20,40$ and $80 \mu \mathrm{M}$ of Cur-NPs for 24 and $48 \mathrm{~h}$. After that, culture medium containing $500 \mu \mathrm{g} / \mathrm{ml}$ MTT was added to each well, and then incubated at $37^{\circ} \mathrm{C}$ for $4 \mathrm{~h}$ before the supernatant was removed. The formed blue formazan crystals in viable CAR cells were dissolved with isopropanol/0.04 $\mathrm{N} \mathrm{HCl}$, followed by measurement of the absorbance of each well at $570 \mathrm{~nm}$ with the ELISA reader with a reference wavelength of $620 \mathrm{~nm}$. All experiments were performed in triplicate. The morphological examination of apoptosis in Cur-NPs-treated CAR cells was determined under a phase-contrast microscope (50).

DAPI staining for apoptosis. CAR cells $\left(5 \times 10^{4}\right.$ cells/well) into 12-well plates were incubated without (control) or with 10, 20 and $40 \mu \mathrm{M}$ of Cur-NPs for $24 \mathrm{~h}$. Cells were washed with PBS and permeabilized in $0.1 \%$ Triton X-100 in PBS for $30 \mathrm{~min}$ after being fixed in $3.8 \%$ formaldehyde for $15 \mathrm{~min}$. Cells were then stained with DAPI $(1 \mu \mathrm{g} / \mathrm{ml})$ in PBS at $37^{\circ} \mathrm{C}$ for $30 \mathrm{~min}$, following utilizing fluorescence microscopy as described elsewhere (51).

Internalization of curcumin. To track the internalization of Cur-NPs, cells ( $1 \times 10^{6}$ cells/plate) were seeded on 6 -well plates and incubated overnight. Subsequently, cells were treated with Cur-NPs containing $40 \mu \mathrm{M}$ curcumin for $24 \mathrm{~h}$. Finally, the cells were washed with PBS twice, and the internalized curcumin were observed under fluorescence microscope with the filter of 488-nm excitation wavelength and 520-nm emission $(30,52)$.
Western blot analysis. CAR cells ( $1 \times 10^{7} / 75-\mathrm{T}$ flask $)$ were treated with $0,10,20,40$ and $80 \mu \mathrm{M}$ of Cur-NPs for $24 \mathrm{~h}$ or $40 \mu \mathrm{M}$ Cur-NPs for 0, 12, 24, 36 and 48 h. Cells were then harvested, lysed and the total proteins were collected by SDS sample buffer. In brief, about $30 \mu \mathrm{g}$ of protein from each treatment was resolved on $10 \%$ SDS-polyacrylamide gel electrophoresis (PAGE) and electro-transferred to the Immobilon-P Transfer Membrane (Merck Millipore). The transferred membranes were blocked in 5\% non-fat dry milk in $20 \mathrm{mM}$ Tris buffered saline $/ 0.05 \%$ Tween-20 for $1 \mathrm{~h}$ at room temperature followed by incubation with appropriate primary antibodies at $4^{\circ} \mathrm{C}$ overnight. At the end of incubation, membranes were washed with Tris-buffered saline/Tween-20 and incubated with secondary antibodies conjugated with HRP. The blots were developed by the chemiluminescence kit and autoradiography was taken using X-ray film. Each membrane was stripped and reprobed with anti- $\beta$-actin antibody (Sigma-Aldrich Corp.) to ensure equal protein loading during the experiments (53).

Real-time PCR analysis. CAR cells at a density of $5 \times 10^{6}$ in T75 flasks were incubated with or without 40 and $80 \mu \mathrm{M}$ of Cur-NPs for $24 \mathrm{~h}$. Cells were collected, and total RNA was extracted by the Qiagen RNeasy mini kit (Qiagen Inc., Valencia, CA, USA). Each RNA sample was individually reverse-transcribed using the High Capacity cDNA Reverse Transcription kits according to the standard protocols (Applied Biosystems, Foster City, CA, USA) (54). Quantitative PCR was assessed for amplifications with 2X SYBR-Green PCR Master mix (Applied Biosystems) and forward (GTGT GGTGAGTCAGGAACCTGTAT) and reverse (TCTCAAT CTCATCCATGGTGACA) primers for MDR1 gene (diallyl sulfide, diallyl disulfide and diallyl trisulfide affect drug resistant gene expression in colo 205 human colon cancer cells in vitro and in vivo). The 7300 Real-Time PCR (Applied Biosystems) was run in triplicate, and each value was expressed as the comparative threshold cycle (CT) method for the housekeeping gene GAPDH as described elsewhere (55).

Calcein-AM assay. CAR cells ( $2 \times 10^{5}$ cells/well) into 12-well plates were treated with or without $0,10,20,40$ and $80 \mu \mathrm{M}$ of Cur-NPs. After a 24-h exposure, cells were washed twice, and $200 \mathrm{nM}$ calcein-AM was added to each incubation medium for $30 \mathrm{~min}$. The specific calcein fluorescence intensity was measured by flow cytometry, and at least ten thousand events were analyzed per sample as previously described (55).

Assays for caspase-3 and caspase-9 activities. CAR cells (approximately $1 \times 10^{7} / 75-\mathrm{T}$ flask) were exposed to $0,10,20$, 40 and $80 \mu \mathrm{M}$ of Cur-NPs for $24 \mathrm{~h}$. Subsequently, cells were harvested, and cell lysates were assessed in accordance with the manufacturer's instruction provided in the caspase- 3 and caspase-9 Colorimetric Assay kits (R\&D Systems Inc.). Cell lysate containing $50 \mu \mathrm{g}$ protein was then incubated for $1 \mathrm{~h}$ at $37^{\circ} \mathrm{C}$ with specific caspase-3 substrate (DEVD-pNA) or caspase-9 substrate (LEHD-pNA) and the reaction buffer (provided in the kits) and determined by measuring $\mathrm{OD}_{405}$ of the released pNA as previously described (56).

Detection of ROS generation. CAR cells $\left(2 \times 10^{5}\right.$ cells/well) were treated with $25 \mu \mathrm{M}$ of Cur-NPs for $0,3,6,12$ and $24 \mathrm{~h}$, 
A
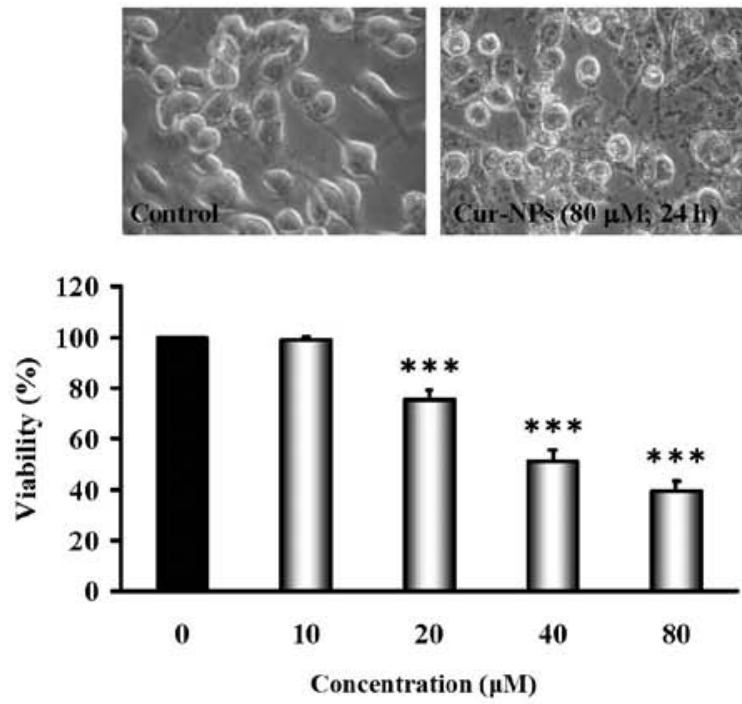

C

Normal human gingival fibroblasts cells (HGF)
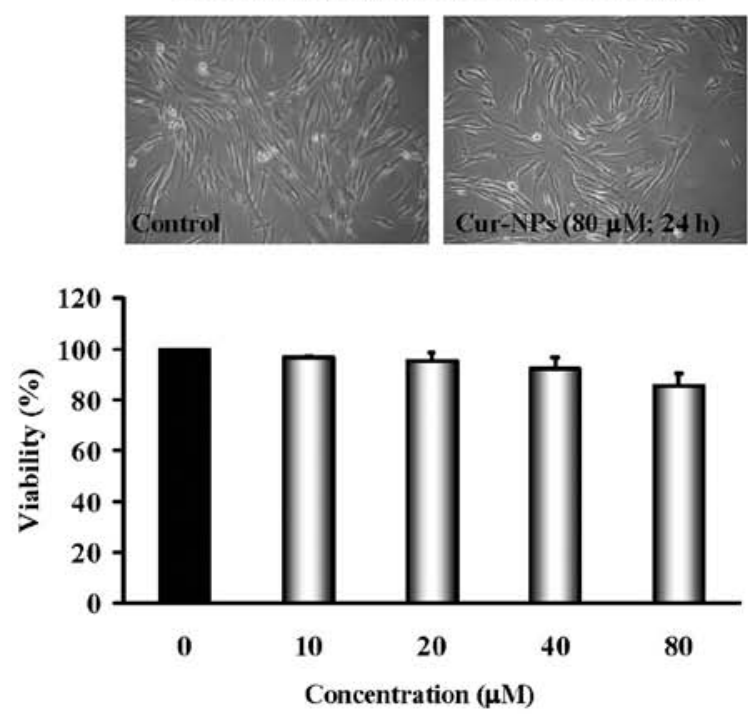

B
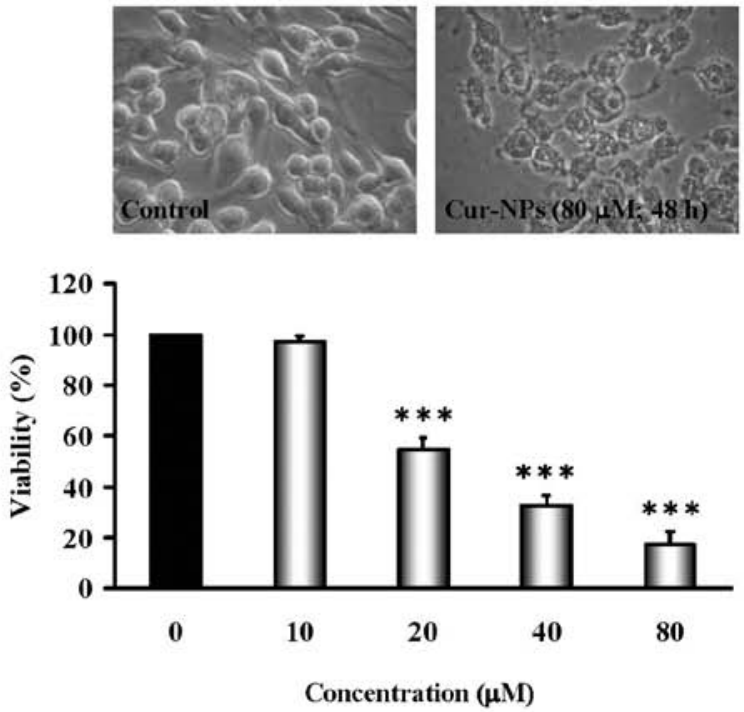

D Normal human oral keratinocyte cells $(\mathrm{OK})$
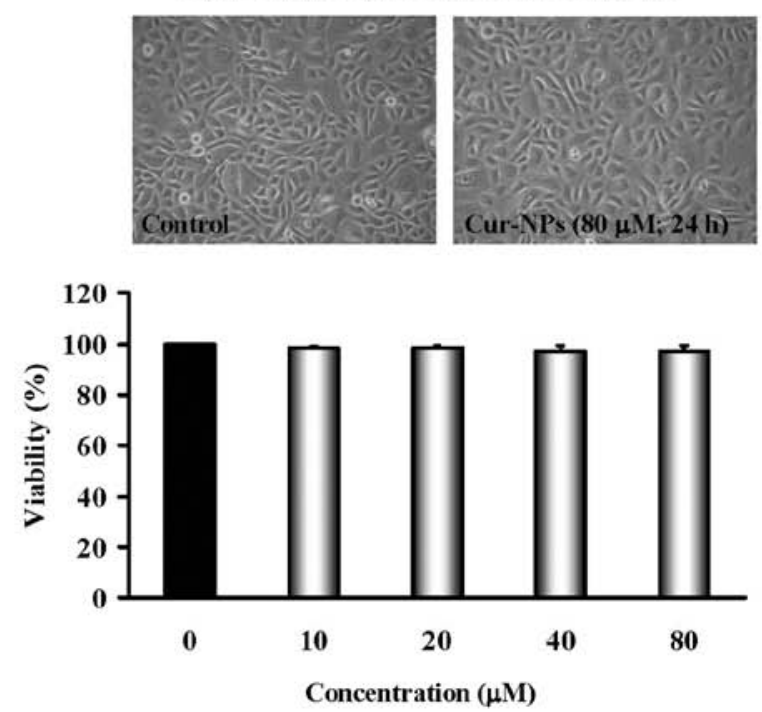

Figure 2. Effects of Cur-NPs on cell viability in CAL27-cisplatin resistant human oral cancer cells (CAR cells) for (A) 24 or (B) 48 h, (C) normal human gingival fibroblasts (HGF) for $48 \mathrm{~h}$ and (D) normal human oral keratinocyte cells (OK) for $48 \mathrm{~h}$. Cells were incubated in the absence or presence of $0,10,20,40$ and $80 \mu \mathrm{M}$ of Cur-NPs for 24 and 48 h. Cell viability on Cur-NPs-treated cells were determined using the MTT assay as described in Materials and methods. The data are presented as mean \pm SEM in triplicate by comparing between the treated and untreated control cells. ${ }^{* * *}$ p $<0.001$ compared with the control value.

harvested, and incubated with $10 \mu \mathrm{M} \mathrm{H} \mathrm{H}_{2} \mathrm{DCFDA}$ at $37^{\circ} \mathrm{C}$ for $30 \mathrm{~min}$. DCF fluorescence oxidized by ROS was detected by flow cytometry as described elsewhere (57).

Effects of the caspase inhibitors and ROS scavenger on cell viability. CAR cells at a density of $2 \times 10^{5}$ cells/well into 12-well plates were preincubated with $10 \mu \mathrm{M}$ z-VAD (a pan-caspase inhibitor), $10 \mu \mathrm{M}$ z-DEVE (a caspase-3 inhibitor), $10 \mu \mathrm{M}$ z-LEHD (a caspase-9 inhibitor) and N-acetyl-L-cysteine (NAC), a ROS scavenger for $2 \mathrm{~h}$ followed by treatment with or without $25 \mu \mathrm{M}$ Cur-NPs. Cells were thereafter harvested at $24 \mathrm{~h}$ to investigate the percentage of viable cells as elsewhere described (57).
Statistical analysis. All the statistical results are performed as the mean \pm standard error of the mean (SEM) for the indicated number of independent experiments. Statistical analyses of data were done using one-way ANOVA followed by Student's t-test, and the levels of $\mathrm{p}<0.001$ was considered significant between the treated and untreated groups (58).

\section{Results}

Cur-NPs reduce the viability of human oral cancer CAL27-cisplatin resistant $(C A R)$ cells, but not the cytotoxic effect on normal cells. CAR cells were exposed to Cur-NPs $(0,10,20,40$ and $80 \mu \mathrm{M})$ for 24 and $48 \mathrm{~h}$, and 
A
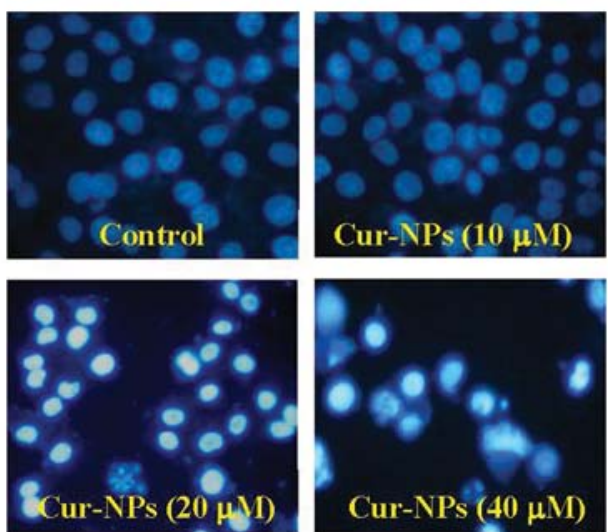

B
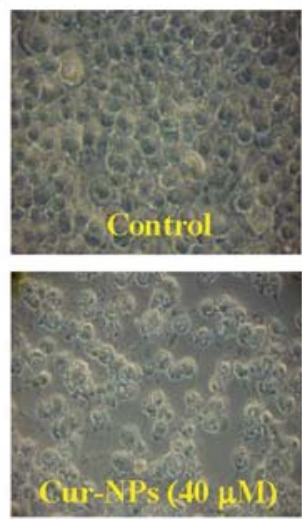
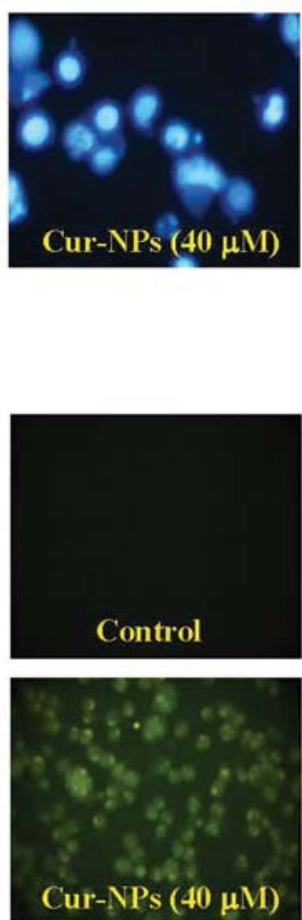

C

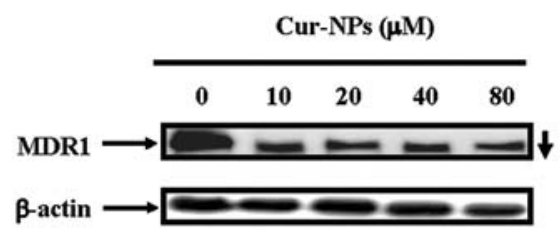

D

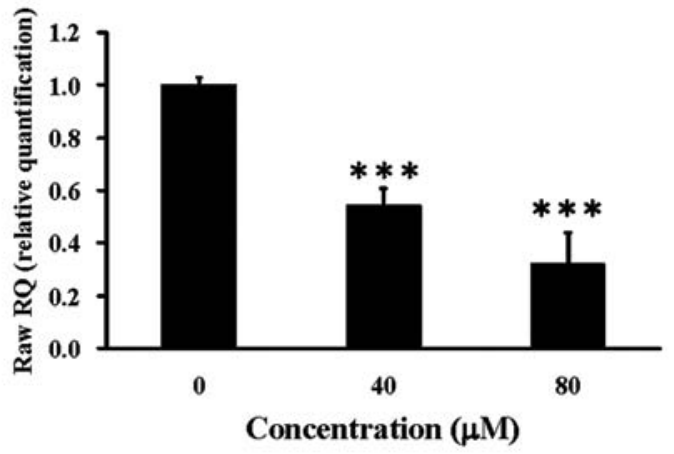

E

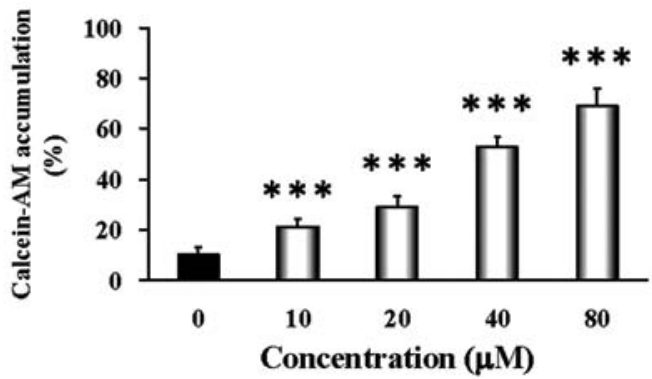

Figure 3. Effects of Cur-NPs on DNA internucleosomal fragmentation, cellular uptake, MDR1 protein and mRNA levels, and calcein-AM accumulation in CAR cells. (A) For DAPI staining, CAR cells were incubated without (control) or with 10,20 and $40 \mu \mathrm{M}$ of Cur-NPs for $48 \mathrm{~h}$. Cells were stained with DAPI dye at $37^{\circ} \mathrm{C}$ for $30 \mathrm{~min}$, followed by fluorescence microscopy. (B) To track the internalization of Cur-NPs, cells were incubated without (control) or with Cur-NPs containing $40 \mu \mathrm{M}$ curcumin for $24 \mathrm{~h}$. The internalized curcumin was observed under a fluorescence microscope with the filter of 488 -nm excitation wavelength and 520 -nm emission. (C) Cells were treated with Cur-NPs 0, 10, 20, 40 and $80 \mu \mathrm{M}$ for $24 \mathrm{~h}$ then subjected to western blot analysis of MDR1 protein level in CAR cells. $\beta$-actin was detected for equivalent protein loading. (D) Cells were treated with Cur-NPs 0,40 and $80 \mu \mathrm{M}$ for $24 \mathrm{~h}$ then subjected to real-time PCR of MDR1 mRNA level in CAR cells. GAPDH was detected for equivalent protein loading. (E) For calcein-AM accumulation, CAR cells in response to $10,20,40$ and $80 \mu$ M Cur-NPs for $24 \mathrm{~h}$ and the calcein-AM accumulation was analyzed by flow cytometry. The data are presented as mean \pm SEM in triplicate by comparing between the treated and untreated control cells. ${ }^{* * *} \mathrm{p}<0.001$ compared with the control value.

cells from each treatment were collected then determined using MTT assay. Results demonstrated that even though $10 \mu \mathrm{M}$ of Cur-NPs showed no effect on viability and the concentrations of Cur-NPs treatment $(20,40$ and $80 \mu \mathrm{M})$ significantly decreased cell viability in CAR cells in a concentration- and time-dependent manner (bottom panels of Fig. 2A and B). The cells after Cur-NPs challenge were investigated for morphological changes such as shrinkage and rounding (an apoptotic characteristic) as can be seen in the top of Fig. 2A and B. Importantly, Cur-NPs have less toxicity (no viability impact and morphological traits) in normal cell lines, including normal human gingival fibroblasts (HGF) and normal human oral keratinocyte cells (OK) $\left(\mathrm{IC}_{50}>80 \mu \mathrm{M}\right)$ (Fig. $2 \mathrm{C}$ and D). These results suggest that Cur-NPs exhibit anticancer action against cisplatinresistant oral tumor cells in vitro.
Cur-NPs induce apoptosis and suppresses multiple drug resistance protein 1 (MDRl) in CAR cells. After treatment with various concentrations $(10,20$ and $40 \mu \mathrm{M})$ of Cur-NPs for $24 \mathrm{~h}$, the ability of induction of nuclear condensation was employed by DAPI staining. The results shown in Fig. 3A revealed apoptotic evidence visualized in Cur-NPs-treated CAR cells and this effect is concentration-dependent. The nanoparticle form of curcumin improves the drawback of curcumin solubility in water and increases the amount of curcumin delivered into cells. Cellular uptake of Cur-NPs was observed by visualizing the green fluorescence of curcumin using fluorescence microscopy (Fig. 3B). Intensified fluorescence was observed in the cytoplasm and nucleus of cells treated with Cur-NPs, indicating the amount of curcumin internalized to the cells. Strikingly, our data indicate attenuation of the expression of MDR1 in Cur-NP-treated CAR cells. 
A

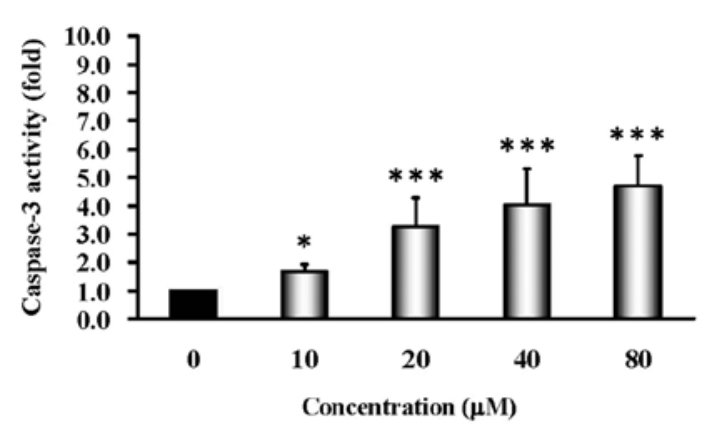

B

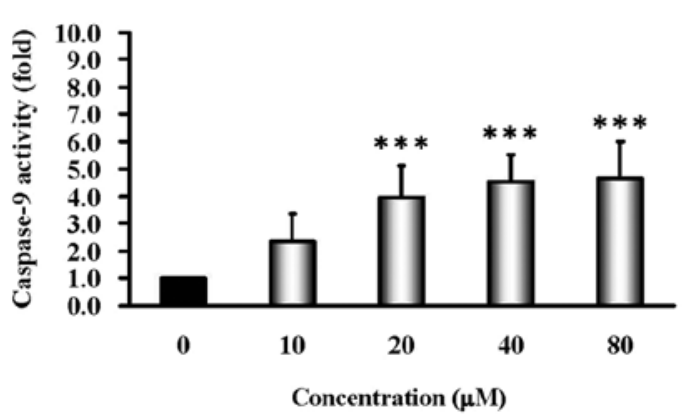

C

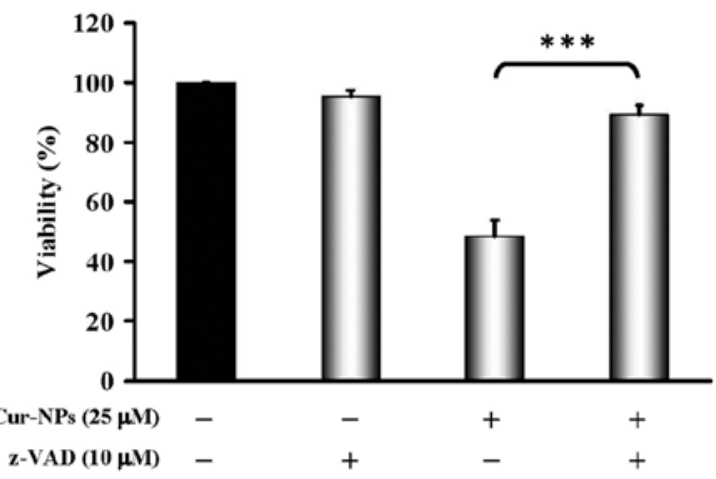

D

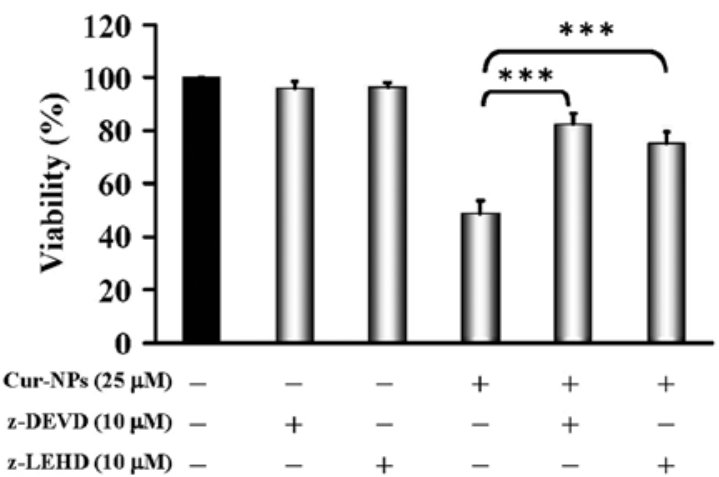

Figure 4. Effects of caspase-9 and caspase-3 are required for Cur-NP-triggered apoptosis of CAR cells. Effects of (A) caspase-9 and (B) caspase-3 activity on Cur-NP-treated CAR cells. Cells were treated with 10, 20, 40 and $80 \mu \mathrm{M}$ Cur-NPs and then incubated for 24 h, and the whole-cell lysate was subjected to caspase activity assay. For cell viability, CAR cells were exposed to $25 \mu \mathrm{M}$ Cur-NPs for $48 \mathrm{~h}$ before pretreatment with or without $10 \mu \mathrm{M}$ of pan-caspase inhibitor (z-VAD-fmk) (C), caspase-9 (z-LEHD-fmk) and caspase-3 inhibitor (z-DEVD-fmk), respectively as described in Materials and methods. The results are shown as mean \pm SEM in triplicate by comparing between the treated and untreated control cells. ${ }^{* * *}$ p $<0.001$ compared with the control value.

We also found that Cur-NPs at 40 and $80 \mu \mathrm{M}$ inhibited the level of MDR1 gene expression in CAR cells (Fig. 3C and D). Alternatively, the drug-resistance expression in CAR cells after exposure to Cur-NPs was detected by calcein-AM staining and flow cytometry. Fig. 3E shows Cur-NPs decreased drug interaction with multidrug resistance protein in CAR cells. Altogether, these results demonstrate that induction of CAR cell apoptosis occurred, as well as suppression of multiple drug resistance by Cur-NPs.

Cur-NPs trigger intrinsic apoptotic cell death in CAR cells. To address whether Cur-NPs induce apoptosis in CAR cells, cells were treated with Cur-NPs $(0,10,20,40$ and $80 \mu \mathrm{M})$ for $24 \mathrm{~h}$ before subjected to caspase-3/-9 activity. Our data as shown in Fig. 4A and B present that Cur-NPs stimulated caspase-3 (Fig. 4A) and caspase-9 (Fig. 4B) activity at a 24-h exposure. In order to confirm the roles of caspase cascade-mediated apoptosis by Cur-NPs, we treated CAR cells without or with z-VAD (a pan-caspase inhibitor), z-DEVE (a caspase-3 inhibitor) and z-LEHD (a caspase-9 inhibitor) before exposure to Cur-NPs to investigate viability. Our data showed that z-VAD significantly suppressed Cur-NPs-reduced viability by up to $90 \%$ in CAR cells (Fig. 4C). Moreover, both caspase protease inhibitors (z-DEVE and z-LEHD) substantially protected against Cur-NP-triggered cell death and viability of CAR cells (Fig. 4D). Based on these findings, we provide evidence that the intrinsic caspase contributed to Cur-NPinduced apoptosis in CAR cells.

Cur-NP enhance ROS generation and promote mitochondria-dependent CAR cell apoptosis. We further clarified if oxidative stress regulates Cur-NP-provoked cell death, and our findings demonstrated that Cur-NPs increased ROS levels in CAR cells as shown in Fig. 5A. Results showed that the presence of NAC dramatically protected CAR cells from cell death (Fig. 5B). We further examined the effects of Cur-NPs on mitochondria-dependent signaling in CAR cells. The immunoblot analysis showed that the protein levels of cleaved caspase-3, cleaved caspase-9, cytochrome $c$, Apaf-1, AIF and Endo G were increased in Cur-NP-treated CAR cells (Fig. 5C). As shown in Fig. 5D, Cur-NP treatment resulted in upregulation of Bax but downregulation of $\mathrm{Bcl}-2$ protein level in treated cells. Thus, we summarize the current understanding in CAR cells that after Cur-NP treatment, cell death is caused through mitochondrial caspase cascade-dependent signals in vitro.

\section{Discussion}

Since poor bioavailability is a major drawback of curcumin, various formulation techniques have been utilized to circumvent this pitfall $(30,59,60)$. Use of nanoparticles is one of the 
A

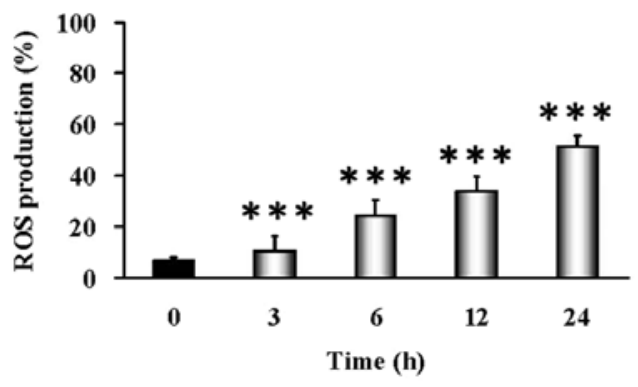

B

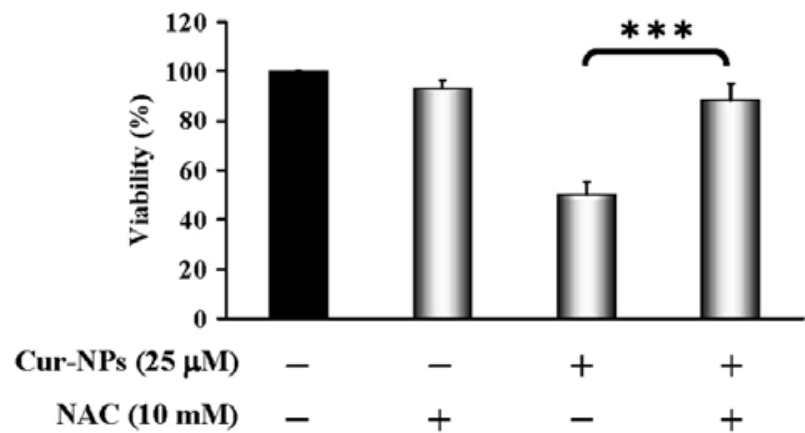

C

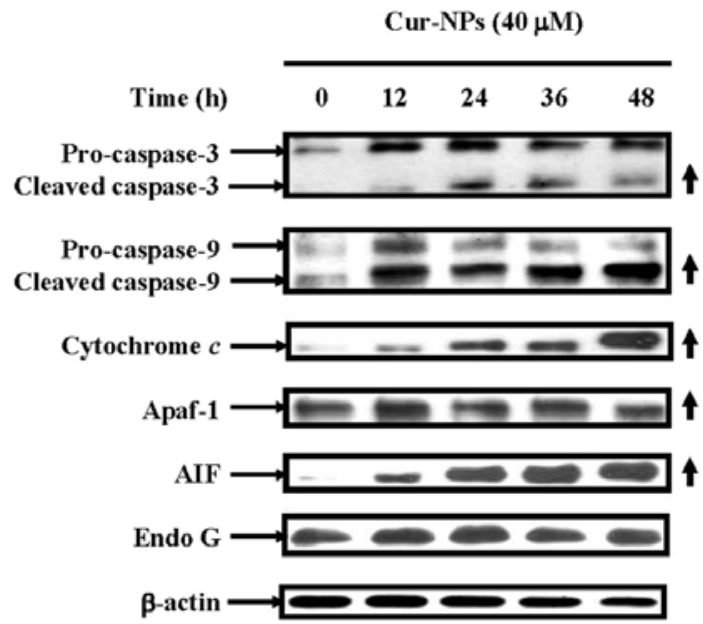

D

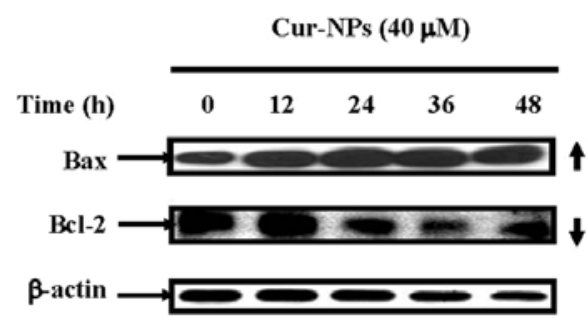

Figure 5. Effects of Cur-NPs caused reactive oxygen species (ROS) production and intrinsic apoptotic signaling pathways in CAR cells. (A) CAR cells in response to $25 \mu \mathrm{M}$ Cur-NPs for $0,3,6,12$ and $24 \mathrm{~h}$ and the reactive oxygen species (ROS) production were analyzed by flow cytometry. (B) For cell viability, CAR cells were exposed to $25 \mu \mathrm{M}$ Cur-NPs for $48 \mathrm{~h}$ before pretreatment with or without $10 \mathrm{mM}$ of antioxidant agent (N-acetylcysteine; NAC), respectively, as described in Materials and methods. Each result is shown as mean \pm SEM in triplicate by comparing between the treated and untreated control cells. ${ }^{* * *}$ p $<0.001$ compared with the control value. The effects of Cur-NPs caused protein level change on intrinsic apoptosis in CAR cells. Cells were treated with $40 \mu \mathrm{M}$ of Cur-NPs for $0,12,24$ 36 and $48 \mathrm{~h}$ then subjected to western blot analysis. The western blot analysis of (C) caspase-3, caspase-9, cytochrome $c$, Apaf-1, AIF, Endo G and (D) Bax, Bcl-1 expression in CAR cells. The $\beta$-actin was detected for equivalent protein loading.

means that have been investigated for this purpose. Anand et al pointed out that nanoparticle-based delivery systems are probably suitable for hydrophobic agents to enhance the solubility of poorly aqua-soluble agents like curcumin (61). In a study reported by Yallapu et al, the curcumin-loaded cellulose nanoparticles showed improved anticancer efficacy compared to free curcumin $(23,52,62)$. Anand et al reported that curcumin-loaded PLGA nanoparticle formulation is at least as potent as, or more potent, than curcumin in inducing cancer cell apoptosis, and has enhanced cellular uptake, increased bioactivity in vitro and superior bioavailability in vivo over curcumin (48). The above-mentioned studies all indicate that Cur-NPs possess significantly greater water solubility and systemic bioavailability than free curcumin $(23,27,46-48)$. It motivated us to design and prepare our own water-soluble curcumin nanoparticles (Cur-NPs) (Fig. 1A) which indeed exhibited anticancer properties in CAL27-cisplatin resistant human CAR oral cancer cells. In the present study, curcumin was successfully incorporated (93.7\%) into PLGA nanoparticles. The morphology of the obtained particles was examined under TEM. Fig. 1B showed that the produced Cur-NPs are spherical in shape with a smooth surface. Measured with dynamic light scattering (DLS), the size of Cur-NPs was on average $180 \mathrm{~nm}$ in diameter (data not shown) which meets the criteria for 'nanoparticles'.

A recent study by Yin et al demonstrated that their Cur-NPs are effective in inhibiting the growth of human lung cancer with little toxicity to normal tissues in an established A549 transplanted mouse model (63). As shown in Fig. 2A and B, the Cur-NPs used in our study also caused anti-proliferation effects on CAR cells in a dose- and time-dependent manner but little cytotoxicity to the normal human gingival fibroblasts cells (HGF) and normal human oral keratinocyte cells (OK) (Fig. 2C and D). The results suggested that Cur-NPs could represent promising candidates as a safe antioral cancer drug.

Overexpression of MDR1 is one of the main reasons for multidrug resistance to chemotherapeutic agents. Misra et al combined doxorubicin and curcumin in PLGA-nanoparticles and found this approach enhanced the cytotoxicity by promoting the apoptotic response in multidrug-resistant K562 leukemia cells (64). Doxorubicin-curcumin composite nanoparticle formulation inhibited the MDR and caused striking growth inhibition both in vitro and in vivo in several models of DOX-resistant myeloma, acute leukemia, prostate cancer and ovarian cancer cells (65). In our preliminary 


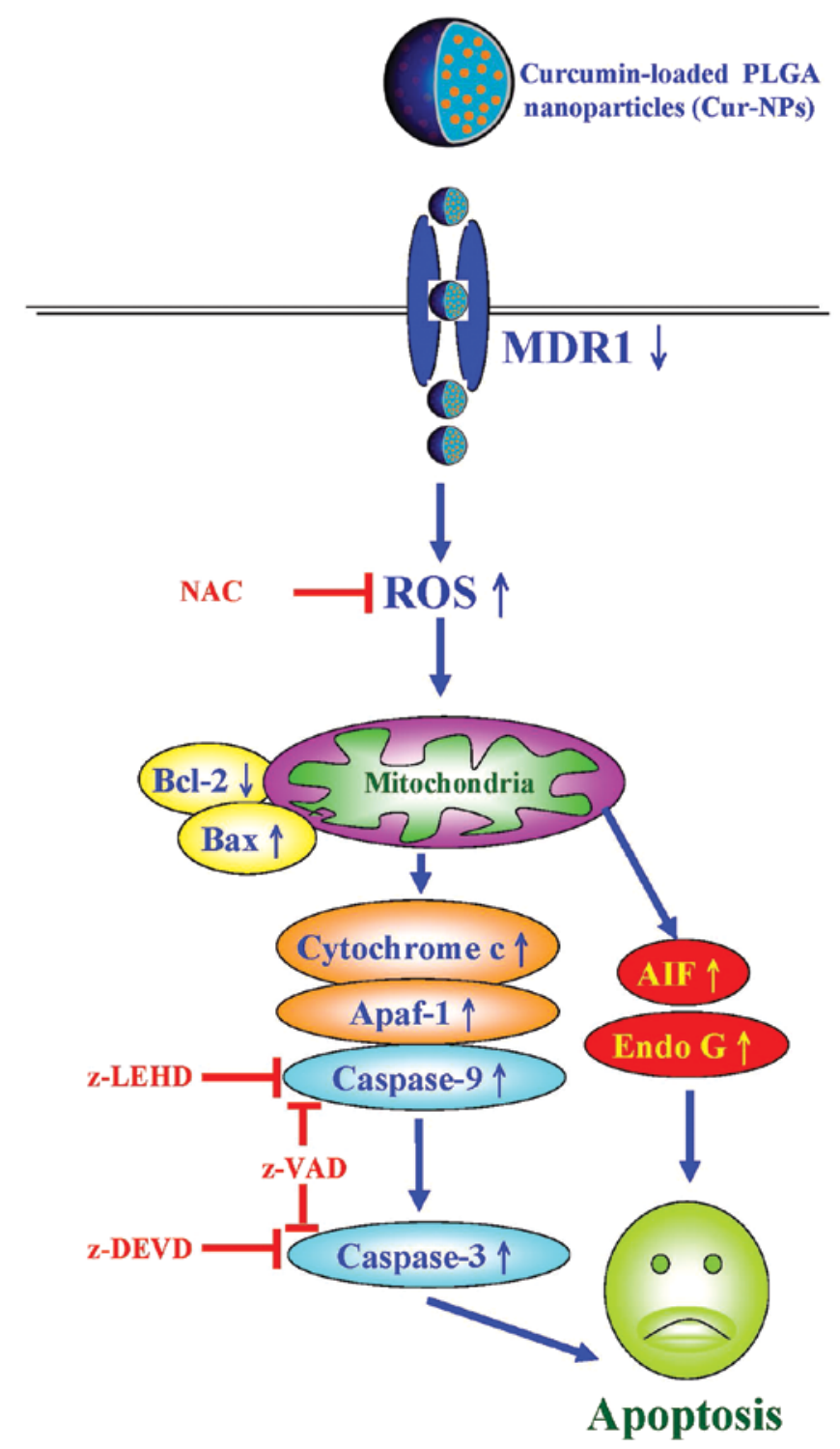

Figure 6. Schematic diagram of molecular mechanism by PLGA nanoparticles loaded with curcumin (Cur-NPs) regulating the signaling pathway leading to apoptosis in CAL27-cisplatin resistant human oral cancer cells (CAR cells).

studies, real-time PCR array analysis revealed higher level of MDR1 expression (ABCB1) in untreated CAR cells than in untreated CAL27 oral cancer cells (data not shown). The results in the present research showed that the mRNA and protein level of MDR1 were both decreased in CAR cells (Fig. 3C and D) after treatment with Cur-NPs. The retention rate of Calcein-AM within Cur-NPs-treated CAR cells (Fig. 3E) indicated that Cur-NPs could reduce the interaction between drugs and multidrug resistance protein in a dose-dependent manner. The data suggested that Cur-NPs induce CAR cell apoptosis via suppressing the expression of multidrug resistance protein due to more retention of the therapeutic medicine within the cells. Some other studies also reported that curcumin downregulates P-glycoprotein (P-gp) expression in drug-resistant SKOV3 human ovarian adenocarcinoma cells through inhibiting $\mathrm{NF}-\kappa \mathrm{B}$ activity $(66,67)$. Punfa et al demonstrated that targeting P-gp on the cell surface membrane of KB-V1 cancer cells (higher expression of P-gp) with Cur-NPs-APgp enhanced the cellular uptake and cytotoxicity of curcumin (68). These results suggested MDR1 or P-gp on the cell surface membrane is the major target of Cur-NPs.

This is the first study investigating the anti-head and neck squamous cell carcinoma effects of Cur-NPs on human CAL27-cisplatin resistant human oral cancer cells (CAR cells). Our results showed that Cur-NPs inhibited CAR cell growth and induced apoptotic cell death in a concentration and time-dependent manner. Fig. 4A and B showed Cur-NPs provoked cell apoptosis through the activation of caspase-9 and caspase-3, whereas a pretreatment of pan-caspase, caspase- 9 and caspase- 3 inhibitors led to increased viable CAR cells compared to the un-pretreated group (Fig. 4C and D). The results suggested that Cur-NPs-induced apoptosis in CAR cells might be carried out through the intrinsic signaling pathway, or mitochdrial-dependent pathway, which has connection with the activation of caspase- 9 and caspase-3.

Various studies reported that curcumin induces apoptosis through intrinsic signaling pathways by depolarizing the mitochondrial membrane and triggering the release of cytochrome $c$ (69-71). Dilnawaz et al utilized curcumin-loaded magnetic nanoparticle (Cur-MNP and Tf-Cur-MNP) formulations to address K562 cells and induced a rapid decrease in mitochondrial membrane potential with release of cytochrome $c$ into cytosol, followed by cleavage of caspase-9 and caspase-3 (72). The result in Fig. 5A shows Cur-NPs provoked intrinsic apoptotic signaling in CAR cells through the production of reactive oxygen species (ROS). More viable CAR cells were preserved when being pretreated with antioxidant agent (N-acetylcysteine; NAC) compared to the un-pretreated group (Fig. 5B). Results of western blot analysis indicated that Cur-NPs elevated the protein level of active form of caspase- 3 and caspase-9 (Fig. 5C), as well as that of cytochrome $c$, Apaf-1, AIF (Fig. 5C) and pro-apoptotic protein Bax (Fig. 5D) while Bcl-2 expression was suppressed (Fig. 5D). Our results suggested that Cur-NP-induced apoptosis could be carried out through the reactive oxygen species (ROS) production.

In summary, Cur-NPs induce cell apoptosis in CAL27-cisplatin resistance human oral cancer cells (CAR cells) and inhibit cell growth but possess little cytotoxicity to normal human gingival fibroblasts cells (HGF) and normal human oral keratinocyte cells (OK). The findings suggest that Cur-NPs trigger apoptotic cell death through regulating the function of MDR1 and the production of reactive oxygen species (ROS), and the activation of caspase- 9 and caspase- 3 connected to intrinsic signaling pathway is the major pharmacologic action of Cur-NPs. Cur-NPs show promise for development as a novel medicine against cisplatin resistant human oral cancer.

\section{Acknowledgements}

This study was supported in part by a research grant from the China Medical University (CMU101-N2-07) to S.-F.P.; and in part by a grant from the National Science Council of Taiwan to T.-S.W. and (102-2320-B-039-028-MY3) awarded to J.-S. Yang. 


\section{References}

1. Nagadia R, Pandit P, Coman WB, Cooper-White J and Punyadeera C: miRNAs in head and neck cancer revisited. Cell Oncol (Dordr) 36: 1-7, 2013.

2. Duvvuri U and Myers JN: Cancer of the head and neck is the sixth most common cancer worldwide. Curr Probl Surg 46: 114-117, 2009.

3. Chen YJ, Chang JT, Liao CT, et al: Head and neck cancer in the betel quid chewing area: recent advances in molecular carcinogenesis. Cancer Sci 99: 1507-1514, 2008.

4. Chang PM, Chen PM, Chu PY, et al: Effectiveness of pharmacokinetic modulating chemotherapy combined with cisplatin as induction chemotherapy in resectable locally advanced head and neck cancer: phase II study. Cancer Chemother Pharmacol 63: 9-17, 2008

5. Chen MK, Su SC, Lin CW, Tsai CM, Yang SF and Weng CJ Cathepsin B SNPs elevate the pathological development of oral cancer and raise the susceptibility to carcinogen-mediated oral cancer. Hum Genet 131: 1861-1868, 2012.

6. Lou JL, Guo L, Zhao JQ and Wang SY: Squamous cell carcinoma of cervical lymph nodes from an unknown primary site: a retrospective analysis of treatment strategies and prognosis. Zhonghua Er Bi Yan Hou Tou Jing Wai Ke Za Zhi 48: 32-36, 2013 (In Chinese).

7. Bose P, Brockton NT and Dort JC: Head and neck cancer: from anatomy to biology. Int J Cancer: Feb 18, 2013 (Epub ahead of print).

8. Kubicek GJ, Kimler BF, Wang F, Reddy EK, Girod DA and Williamson SK: Chemotherapy in head and neck cancer: clinical predictors of tolerance and outcomes. Am J Clin Oncol 34: 380-384, 2011

9. Rades D, Ulbricht T, Hakim SG and Schild SE: Cisplatin superior to carboplatin in adjuvant radiochemotherapy for locally advanced cancers of the oropharynx and oral cavity. Strahlenther Onkol 188: 42-48, 2012.

10. Mandic R, Rodgarkia-Dara CJ, Krohn V, Wiegand S, Grenman R and Werner JA: Cisplatin resistance of the HNSCC cell line UT-SCC-26A can be overcome by stimulation of the EGF-receptor. Anticancer Res 29: 1181-1187, 2009.

11. Sunwoo JB: A cisplatin-resistant subpopulation of mesenchymal-like cells in head and neck squamous cell carcinoma. Cell Cycle 10: 2834-2835, 2011.

12. Vyas A, Dandawate P, Padhye S, Ahmad A and Sarkar F: Perspectives on new synthetic curcumin analogs and their potential anticancer properties. Curr Pharm Des 19: 2047-2069, 2013.

13. Baliga MS, Joseph N, Venkataranganna MV, Saxena A Ponemone V and Fayad R: Curcumin, an active component of turmeric in the prevention and treatment of ulcerative colitis: preclinical and clinical observations. Food Funct 3: 1109-1117, 2012.

14. Hanai $\mathrm{H}$ and Sugimoto K: Curcumin has bright prospects for the treatment of inflammatory bowel disease. Curr Pharm Des 15: 2087-2094, 2009

15. Li Y and Wang P: Neuroprotective effects of curcumin. Zhongguo Zhong Yao Za Zhi 34: 3173-3175, 2009 (In Chinese)

16. Shishodia S: Molecular mechanisms of curcumin action: gene expression. Biofactors 39: 37-55, 2013.

17. Noorafshan A and Ashkani-Esfahani S: A review of therapeutic effects of curcumin. Curr Pharm Des 19: 2032-2046, 2013

18. Zhang X, Chen LX, Ouyang L, Cheng Y and Liu B: Plant natural compounds: targeting pathways of autophagy as anticancer therapeutic agents. Cell Prolif 45: 466-476, 2012

19. Ye MX, Li Y, Yin H and Zhang J: Curcumin: updated molecular mechanisms and intervention targets in human lung cancer. Int J Mol Sci 13: 3959-3978, 2012.

20. Saha S, Adhikary A, Bhattacharyya P, Das T and Sa G: Death by design: where curcumin sensitizes drug-resistant tumours. Anticancer Res 32: 2567-2584, 2012.

21. Gupta SC, Kismali G and Aggarwal BB: Curcumin, a component of turmeric: from farm to pharmacy. Biofactors 39: 2-13, 2013.

22. Gao W, Chan JY, Wei WI and Wong TS: Anti-cancer effects of curcumin on head and neck cancers. Anticancer Agents Med Chem 12: 1110-1116, 2012.

23. Yallapu MM, Jaggi M and Chauhan SC: Curcumin nanoformulations: a future nanomedicine for cancer. Drug Discov Today 17: 71-80, 2012.

24. Varinska L, Mirossay L, Mojzisova G and Mojzis J: Antiangogenic effect of selected phytochemicals. Pharmazie 65: 57-63, 2010.
25. Basnet $\mathrm{P}$ and Skalko-Basnet N: Curcumin: an anti-inflammatory molecule from a curry spice on the path to cancer treatment. Molecules 16: 4567-4598, 2011.

26. Haddad M, Sauvain M and Deharo E: Curcuma as a parasiticidal agent: a review. Planta Med 77: 672-678, 2011.

27. Ji JL, Huang XF and Zhu HL: Curcumin and its formulations: potential anti-cancer agents. Anticancer Agents Med Chem 12: 210-218, 2012

28. Shehzad A, Wahid F and Lee YS: Curcumin in cancer chemoprevention: molecular targets, pharmacokinetics, bioavailability, and clinical trials. Arch Pharm (Weinheim) 343: 489-499, 2010.

29. Epstein J, Sanderson IR and Macdonald TT: Curcumin as a therapeutic agent: the evidence from in vitro, animal and human studies. Br J Nutr 103: 1545-1557, 2010.

30. Yallapu MM, Ebeling MC, Khan S, et al: Novel curcumin loaded magnetic nanoparticles for pancreatic cancer treatment. Mol Cancer Ther: May 23, 2013 (Epub ahead of print).

31. Pawar YB, Purohit H, Valicherla GR, et al: Novel lipid based oral formulation of curcumin: development and optimization by design of experiments approach. Int J Pharm 436: 617-623, 2012.

32. Gupta NK and Dixit VK: Bioavailability enhancement of curcumin by complexation with phosphatidyl choline. J Pharm Sci 100: 1987-1995, 2011.

33. Verderio P, Bonetti P, Colombo M, Pandolfi L and Prosperi D: Intracellular drug release from curcumin-loaded PLGA nanoparticles induces $\mathrm{G} 2 / \mathrm{M}$ block in breast cancer cells. Biomacromolecules 14: 672-682, 2013.

34. Tsai YM, Chang-Liao WL, Chien CF, Lin LC and Tsai TH: Effects of polymer molecular weight on relative oral bioavailability of curcumin. Int J Nanomed 7: 2957-2966, 2012.

35. Doggui S, Sahni JK, Arseneault M, Dao L and Ramassamy C: Neuronal uptake and neuroprotective effect of curcuminloaded PLGA nanoparticles on the human SK-N-SH cell line. J Alzheimers Dis 30: 377-392, 2012.

36. Das M and Sahoo SK: Folate decorated dual drug loaded nanoparticle: role of curcumin in enhancing therapeutic potential of nutlin-3a by reversing multidrug resistance. PLoS One 7: e32920, 2012.

37. Xie X, Tao Q, Zou Y, et al: PLGA nanoparticles improve the oral bioavailability of curcumin in rats: characterizations and mechanisms. J Agric Food Chem 59: 9280-9289, 2011.

38. Bansal SS, Goel M, Aqil F, Vadhanam MV and Gupta RC: Advanced drug delivery systems of curcumin for cancer chemoprevention. Cancer Prev Res (Phila) 4: 1158-1171, 2011.

39. Jain AK, Das M, Swarnakar NK and Jain S: Engineered PLGA nanoparticles: an emerging delivery tool in cancer therapeutics. Crit Rev Ther Drug Carrier Syst 28: 1-45, 2011.

40. Berginc K, Trontelj J, Basnet NS and Kristl A: Physiological barriers to the oral delivery of curcumin. Pharmazie 67: $518-524,2012$

41. Shukla S,ZaherH,Hartz A, Bauer B, Ware JA and Ambudkar SV: Curcumin inhibits the activity of ABCG2/BCRP1, a multidrug resistance-linked ABC drug transporter in mice. Pharm Res 26: 480-487, 2009.

42. Yue GG, Cheng SW, Yu H, et al: The role of turmerones on curcumin transportation and P-glycoprotein activities in intestinal Caco-2 cells. J Med Food 15: 242-252, 2012.

43. Zhou S, Lim LY and Chowbay B: Herbal modulation of P-glycoprotein. Drug Metab Rev 36: 57-104, 2004.

44. Gosepath EM, Eckstein N, Hamacher A, et al: Acquired cisplatin resistance in the head-neck cancer cell line Cal27 is associated with decreased DKK1 expression and can partially be reversed by overexpression of DKK1. Int J Cancer 123: 2013-2019, 2008

45. Shih YH, Chang KW, Hsia SM, et al: In vitro antimicrobial and anticancer potential of hinokitiol against oral pathogens and oral cancer cell lines. Microbiol Res 168: 254-262, 2013.

46. Mathew A, Fukuda T, Nagaoka Y, et al: Curcumin loadedPLGA nanoparticles conjugated with Tet-1 peptide for potential use in Alzheimer's disease. PLoS One 7: e32616, 2012.

47. Luz PP, Magalhaes LG, Pereira AC, Cunha WR, Rodrigues V and Andrade ESML: Curcumin-loaded into PLGA nanoparticles: preparation and in vitro schistosomicidal activity. Parasitol Res 110: 593-598, 2012.

48. Anand P, Nair HB, Sung B, et al: Design of curcumin-loaded PLGA nanoparticles formulation with enhanced cellular uptake, and increased bioactivity in vitro and superior bioavailability in vivo. Biochem Pharmacol 79: 330-338, 2010.

49. Koppolu B, Rahimi M, Nattama S, Wadajkar A and Nguyen KT: Development of multiple-layer polymeric particles for targeted and controlled drug delivery. Nanomedicine 6: 355-361, 2010. 
50. Chang CM, Chang PY, Tu MG, et al: Epigallocatechin gallate sensitizes CAL-27 human oral squamous cell carcinoma cells to the anti-metastatic effects of gefitinib (Iressa) via synergistic suppression of epidermal growth factor receptor and matrix metalloproteinase-2. Oncol Rep 28: 1799-1807, 2012.

51. Tsai SC, Lu CC, Lee CY, et al: AKT serine/threonine protein kinase modulates bufalin-triggered intrinsic pathway of apoptosis in CAL 27 human oral cancer cells. Int J Oncol 41 1683-1692, 2012.

52. Yallapu MM, Othman SF, Curtis ET, et al: Curcumin-loaded magnetic nanoparticles for breast cancer therapeutics and imaging applications. Int J Nanomed 7: 1761-1779, 2012.

53. Tsai SC, Yang JS, Peng SF, et al: Bufalin increases sensitivity to AKT/mTOR-induced autophagic cell death in SK-HEP-1 human hepatocellular carcinoma cells. Int J Oncol 41: 1431-1442, 2012.

54. Mozaffarieh M, Konieczka K, Hauenstein D, Schoetzau A and Flammer J: Half a pack of cigarettes a day more than doubles DNA breaks in circulating leukocytes. Tob Induc Dis 8: 14, 2010.

55. Kuo TC, Yang JS, Lin MW, et al: Emodin has cytotoxic and protective effects in rat C6 glioma cells: roles of Mdrla and nuclear factor kappaB in cell survival. J Pharmacol Exp Ther 330: 736-744, 2009

56. Huang WW, Tsai SC, Peng SF, et al: Kaempferol induces autophagy through AMPK and AKT signaling molecules and causes $\mathrm{G} 2 / \mathrm{M}$ arrest via downregulation of CDK1/cyclin B in SK-HEP-1 human hepatic cancer cells. Int J Oncol 42: 2069-2077, 2013.

57. Lan YH, Chiang JH, Huang WW, et al: Activations of both extrinsic and intrinsic pathways in HCT 116 human colorectal cancer cells contribute to apoptosis through p53-mediated ATM/Fas signaling by Emilia sonchifolia extract, a folklore medicinal plant. Evid Based Complement Alternat Med 2012: 178178, 2012.

58. Lin C, Tsai SC, Tseng MT, et al: AKT serine/threonine protein kinase modulates baicalin-triggered autophagy in human bladder cancer T24 cells. Int J Oncol 42: 993-1000, 2013.

59. Taurin S, Nehoff H, Diong J, Larsen L, Rosengren RJ and Greish K: Curcumin-derivative nanomicelles for the treatment of triple negative breast cancer. J Drug Target: May 16, 2013 (Epub ahead of print).

60. Yen FL, Wu TH, Tzeng CW, Lin LT and Lin CC: Curcumin nanoparticles improve the physicochemical properties of curcumin and effectively enhance its antioxidant and antihepatoma activities. J Agric Food Chem 58: 7376-7382, 2010.
61. Anand P, Kunnumakkara AB, Newman RA and Aggarwal BB: Bioavailability of curcumin: problems and promises. Mol Pharm 4: 807-818, 2007.

62. Yallapu MM, Dobberpuhl MR, Maher DM, Jaggi $M$ and Chauhan SC: Design of curcumin loaded cellulose nanoparticles for prostate cancer. Curr Drug Metab 13: 120-128, 2012.

63. Yin HT, Zhang DG, Wu XL, Huang XE and Chen G: In vivo evaluation of curcumin-loaded nanoparticles in a A549 xenograft mice model. Asian Pac J Cancer Prev 14: 409-412, 2013.

64. Misra R and Sahoo SK: Coformulation of doxorubicin and curcumin in poly(D,L-lactide-co-glycolide) nanoparticles suppresses the development of multidrug resistance in K562 cells. Mol Pharm 8: 852-866, 2011.

65. Pramanik D, Campbell NR, Das S, et al: A composite polymer nanoparticle overcomes multidrug resistance and ameliorates doxorubicin-associated cardiomyopathy. Oncotarget 3: 640-650, 2012

66. Ganta S, Devalapally H and Amiji M: Curcumin enhances oral bioavailability and anti-tumor therapeutic efficacy of paclitaxel upon administration in nanoemulsion formulation. J Pharm Sci 99: 4630-4641, 2010.

67. Ganta S and Amiji M: Coadministration of Paclitaxel and curcumin in nanoemulsion formulations to overcome multidrug resistance in tumor cells. Mol Pharm 6: 928-939, 2009.

68. Punfa W, Yodkeeree S, Pitchakarn P, Ampasavate C and Limtrakul P: Enhancement of cellular uptake and cytotoxicity of curcumin-loaded PLGA nanoparticles by conjugation with anti-P-glycoprotein in drug resistance cancer cells. Acta Pharmacol Sin 33: 823-831, 2012.

69. Cort A, Ozdemir E, Timur M and Ozben T: Effects of curcumin on bleomycininduced oxidative stress in malignant testicular germ cell tumors. Mol Med Rep 6: 860-866, 2012.

70. Misra J, Chanda D, Kim DK, et al: Curcumin differentially regulates endoplasmic reticulum stress through transcriptional corepressor SMILE (small heterodimer partner-interacting leucine zipper protein)-mediated inhibition of CREBH (cAMP responsive element-binding protein $\mathrm{H}$ ). J Biol Chem 286: 41972-41984, 2011.

71. Wahl H, Tan L, Griffith K, Choi M and Liu JR: Curcumin enhances Apo2L/TRAIL-induced apoptosis in chemoresistant ovarian cancer cells. Gynecol Oncol 105: 104-112, 2007.

72. Dilnawaz F, Singh A and Sahoo SK: Transferrin-conjugated curcumin-loaded superparamagnetic iron oxide nanoparticles induce augmented cellular uptake and apoptosis in K562 cells. Acta Biomater 8: 704-719, 2012. 